\title{
Hydrodynamic Analysis in Redesigning a Monohull Passenger Ship into a Catamaran
}

\author{
Ivory Giyan Mitari ${ }^{1}$, Wiwin Sulistyawati ${ }^{2}$, Purwo Joko Suranto ${ }^{2}$ \\ ${ }^{1}$ Undergraduate Student of Naval Engineering, Faculty of Engineering, University of Pembangunan Nasional Veteran Jakarta, \\ Indonesia \\ ${ }^{2}$ Faculty of Engineering, University of Pembangunan Nasional Veteran Jakarta Indonesia
}

\begin{abstract}
In line with technological developments, many studies have led to the factors that consider hull shape planning. Therefore, innovations in hull form planning are the primary basis for obtaining a hull that is considered efficient in reducing ship resistance and fuel consumption. This study aims to modify the design of a monohull and transform it into a catamaran while maintaining the total length and Displacement ratio. The ship model used is the Monohull passenger ship with a rounded shape and modified to become a catamaran with a chine shape. The hull chine symmetrical was determined by stagger to the length ratio of $\mathrm{S} / \mathrm{L}$ 0.3. The hydrodynamic investigations and calculations of models using Computational Fluid Dynamic (CFD). Analysis hydrodynamic on both hulls carried out on the components of total resistance, viscous resistance, friction resistance, and wave resistance with variations of Froude number: 0.3: 0.5: 0.7: 0.9 and 1.2. From the results of the analysis, it is found that the calculation of the coefficient of resistance on the catamaran with the Chine hull is smaller than the monohull. Fn 0.7 at $\mathrm{S} / \mathrm{L} 0.3$, the catamaran produces a resistance coefficient that is more favorable than the other speeds.
\end{abstract}

Keywords: Catamaran, CFD, Hydrodynamic Analysis

\section{Introduction}

Technological developments in the shipping sector have made many innovations in the hull and several aspects of efforts to reduce fuel consumption. In this endeavor, the effort to reduce resistance which has received significant attention is multihulls. Many studies have noted that multihulls have less drag than monohulls at high speeds. Other advantages include a more deck area and a larger volume of space. Multihull research was first conducted by [1], who analyzed the interference between 2 parallel flat plates and then developed into a catamaran. Furthermore, it has been found that the multihull is very determined changes in the ratio of stagger to the length of the ship $(\mathrm{S} / \mathrm{L})$, which affects the wave interference that occurs. The results in one of them discussed by [2]-[4], where the more significant the distance of the $\mathrm{S} / \mathrm{L}$ ratio, the smaller the wave interference that occurs.

Another aspect of resistance reduction is the hull shape of the ship. Changes in the hull's shape are often considered for hydrodynamic factors that can make ships more efficient. This shape is very influential on the reduction of the multihull resistance component in addition to the selection of the proper outrigger configuration. According to [5]-[7], the slender hull shape on fast boats is the power to achieve minimum wave resistance. [8][9] stated that the optimum hull form manifests the minimum total resistance value: viscous and wave-making.

This study aims to modify the monohull passenger ship into a catamaran by maintaining the ratio main dimension and volume displacement. Modifications were also made to the initial rounded shape into a chine shape. The $\mathrm{S} / \mathrm{L}$ distance ratio was determined at 0.3 by varying speeds/ Froude numbers. Comparative analysis of monohull and catamaran using CFD software and several ship modeling tools. Investigations were carried out on the ship's resistance component and the wave pattern that occurs from both.

\section{Ship's Resistance}

A moving ship experiences a force opposite to the direction of its motion that is referred to as the ship's resistance or "total hull resistance". The force is influenced by factors: the ship's speed, the shape of the hull, the wetted surface area, and the water temperature. The ship's movement will produce wave characteristics formed from the bow and stern of the ship and air resistance from the ship's movement. The total resistance can be written:

\footnotetext{
*Corresponding author : wiwinsulistyawati@upnvj.ac.id
} 


$$
R_{T}=R_{V}+R_{W}+R_{A A}
$$

where $R_{T}$, total hull resistance; $R_{V}$, viscous (friction) resistance; $R_{W}$, wave-making resistance; $R_{A A}$, air resistance caused by a ship moving through calm air. Based on Froude's hypothesis, this total resistance can be summarized into frictional resistance $\left(R_{F}\right)$ and residual resistance $\left(R_{R}\right)$.

$$
R_{T}=R_{F}+R_{R}
$$

Following the International Towing Tank Conference (ITTC) 1957, the determination of the coefficient of friction $\left(C_{F}\right)$ :

$$
\begin{gathered}
C_{F}=\frac{0.075}{(\log R n-2)^{2}} \\
C_{T}=C_{W}+(k+1) C_{F} \\
C_{T}=C_{W}+C_{V}
\end{gathered}
$$

These coefficients make it possible to compare hydrodynamic performance data from several types of vessels.

\section{Ship Analysis}

Experimental techniques in ship hydrodynamic analysis have been tested with advantages in identifying actual conditions. However, the CFD simulation approach is more attractive, fast, and inexpensive, although it is not entirely identifiable. To develop a numerical to calculate the ship's dimensions and hydrodynamic analysis data that is sufficient to provide the best technological solution. This study uses CFD by classifying the elements of analysis according to existing locations and referring to the ITTC 2011 (International Towing Tank Convention) rules regarding "Practical Guidelines for Ship CFD Applications"[10].

The hull model is using the motorboat Petrus Sianturi, a traditional boat crossing on Lake Toba. This boat is from the Research and Development Center for SDP sea transportation, the Indonesian Transportation Research, and Development Agency. The main dimensions are shown in Table 1 . The main dimensions after modeling and the lines plan of Monohull are shown in Table 2 and Figure 1, respectively.

Table 1. Main properties of motorboat Peter Sianturi

\begin{tabular}{|l|c|}
\hline \multicolumn{1}{|c|}{ Parameter } & Dimension \\
\hline Length Overall (LOA) & $19 \mathrm{~m}$ \\
\hline Length Between Perpendicular (LPP) & $16.6 \mathrm{~m}$ \\
\hline Breadth (B) & $6.9 \mathrm{~m}$ \\
\hline Height $(\mathrm{H})$ & $1.65 \mathrm{~m}$ \\
\hline Draught $(\mathrm{T})$ & $0.6 \mathrm{~m}$ \\
\hline Coefficient Block $\left(\mathrm{C}_{\mathrm{B}}\right)$ & 0.42 \\
\hline Coefisien of Midship $\left(\mathrm{C}_{\mathrm{M}}\right)$ & 0.6 \\
\hline Coefisien Waterline $\left(\mathrm{C}_{\mathrm{W}}\right)$ & 0.71 \\
\hline Displacement $(\Delta)$ & $25.65 \mathrm{Ton}$ \\
\hline
\end{tabular}

Table 2. Main properties of Monohull

\begin{tabular}{|l|c|}
\hline \multicolumn{1}{|c|}{ Parameter } & Dimension \\
\hline Length Overall (LOA) & $1.9 \mathrm{~m}$ \\
\hline $\begin{array}{l}\text { Length Between Perpendicular } \\
\text { (LPP) }\end{array}$ & $1.822 \mathrm{~m}$ \\
\hline Breadth $(\mathrm{B})$ & $0.69 \mathrm{~m}$ \\
\hline Height $(\mathrm{H})$ & $0.184 \mathrm{~m}$ \\
\hline Draught $(\mathrm{T})$ & $0.06 \mathrm{~m}$ \\
\hline Coefficient Block $\left(\mathrm{C}_{\mathrm{B}}\right)$ & 0.043 \\
\hline Coefisien of Midship $\left(\mathrm{C}_{\mathrm{M}}\right)$ & 0.067 \\
\hline Coefisien Waterline $\left(\mathrm{C}_{\mathrm{W}}\right)$ & 0.07 \\
\hline Displacement $(\Delta)$ & $2.565 \mathrm{Ton}$ \\
\hline
\end{tabular}

BDDY PLAN

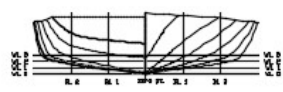

SHEER PLAN

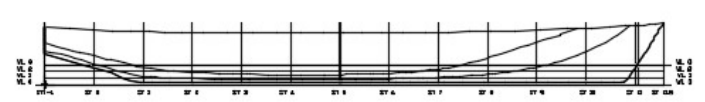

HALF BREADTH PLAN

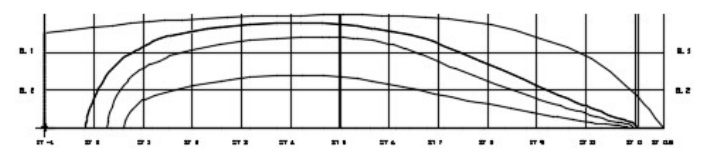

Fig. 1. Lines plan of Monohull

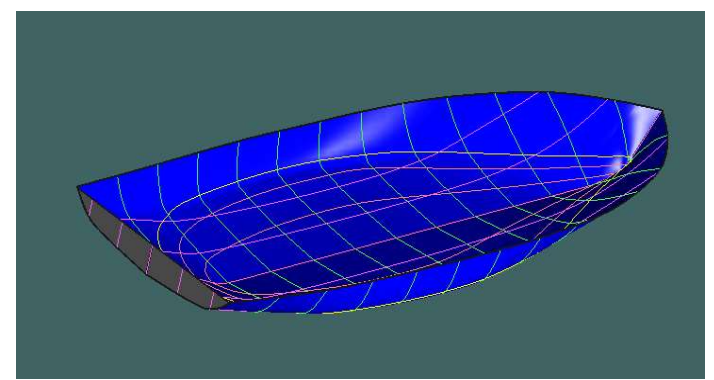

Fig. 2. 3D modelling of Monohull

Modify the monohull motorboat into a catamaran by setting at the same total length and displacement. The ratio of stagger to length is determined by $\mathrm{S} / \mathrm{L} 0.3$ measured from the center of each hull on a scale of $1: 10$. The modifying of the motorboat hull into a catamaran with a chine hull is shown in Table 3 and Figures 3-4, respectively. The hull chine was chosen that this shape can reduce wave resistance, and the interference will tend to decrease at $\mathrm{Fr}>0.5$. Moreover, based on the experiments of [11][12], the hydrodynamic of the hull chine at a deadrise angle of $0^{\circ}-20^{\circ}$ can increase the lift coefficient. 


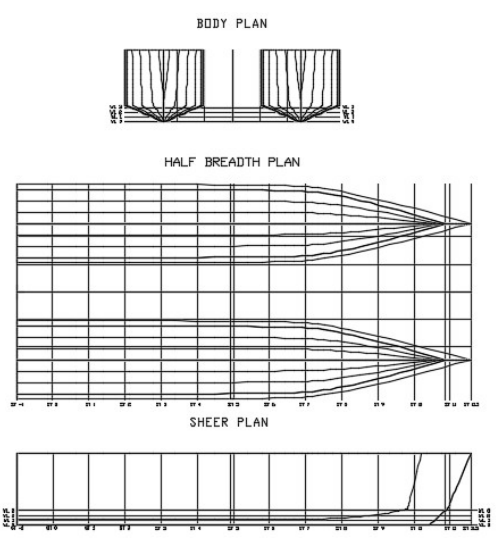

Fig. 3. Lines Plan Catamaran

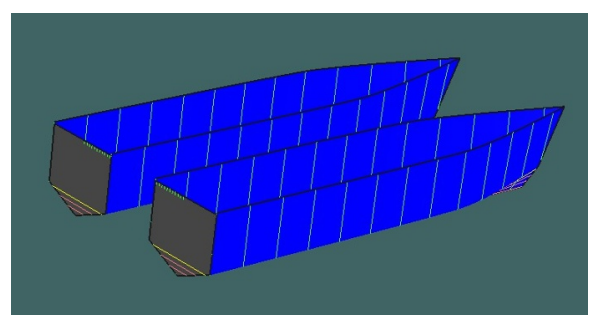

Fig. 4. Catamaran Ship Model

Table 3. Main properties of catamaran

\begin{tabular}{|l|c|}
\hline \multicolumn{1}{|c|}{ Parameter } & Dimension \\
\hline Length Overall (LOA) & $1.9 \mathrm{~m}$ \\
\hline $\begin{array}{l}\text { Length Between Perpendicular } \\
\text { (LPP) }\end{array}$ & $1.793 \mathrm{~m}$ \\
\hline Breadth (B) & $0.898 \mathrm{~m}$ \\
\hline Height $(\mathrm{H})$ & $0.3 \mathrm{~m}$ \\
\hline Draught $(\mathrm{T})$ & $0.06 \mathrm{~m}$ \\
\hline Coefisien Block $\left(\mathrm{C}_{\mathrm{B}}\right)$ & 0.028 \\
\hline Coefisien of Midship $\left(\mathrm{C}_{\mathrm{M}}\right)$ & 0.033 \\
\hline Coefisien Waterline $\left(\mathrm{C}_{\mathrm{W}}\right)$ & 0.056 \\
\hline Total Displacement $(\Delta)$ & $2.565 \mathrm{Ton}$ \\
\hline
\end{tabular}

The initial process in this simulation uses ICEM with an iterative meshing process to produce convergent values. The model domain boundaries refer to the 2011 ITTC rules, as shown in Figure 5. The inlet is set at 2 Lpp from the bow, while the outlet is 2 Lpp from the stern. The side is at $1 \mathrm{Lpp}$ from the symmetry plane, the bottom $1 \mathrm{Lpp}$ from the keel, and the top $0.5 \mathrm{Lpp}$ from the model's keel.
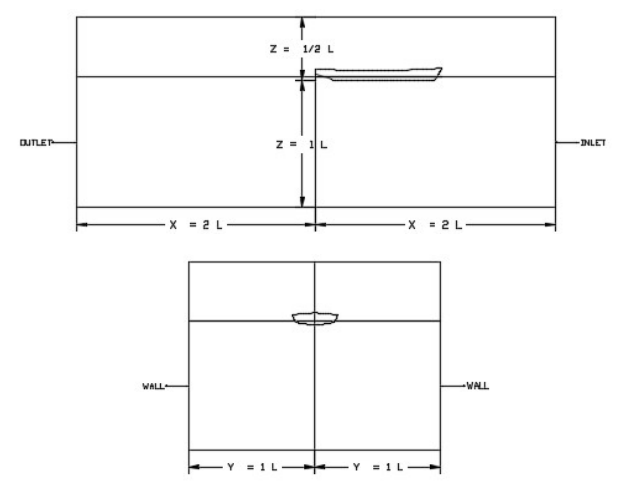

Fig. 5. Setting boundary conditions on CFD

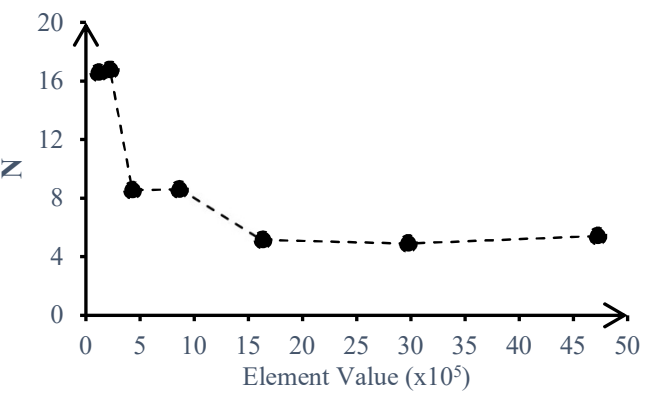

Fig. 6. Convergence process

The analysis of the resistance solution was verified using element number convergence on meshing and numerical uncertainty evaluation. The mesh processing repeated up to seven times with element sizes for both the boundary and hull in 0.2 to 0.034 . Convergence is obtained when the value of the force difference is not significant, as shown in Figure 6. The physical domain in the free surface model for the domain boundary was defined: mesh tetrahedral, mixer; physics domain: homogeneous water/air multiphase, K- $\varepsilon$ based on [13], automatic wall function, and standard free surface model; inlet: volume fraction, turbulence intensity 0.034; an outlet, relative pressure; wall, free slip condition; top, Opening, relative pressure $0 \mathrm{~Pa}$; hull and bottom, a wall with a no-slip condition; solver settings with convergence criteria on residuary type RMS, Target: 10-e4; and multiphase control used Volume fraction coupling. Furthermore, in analyzing the resistance component, it is calculated through the process of CFX. That CFX uses a robust implicit formulation that allows significant time steps to be determined and accelerates convergence. The time step allows a fixed time step size to be used for the entire flow domain. The flow is dominated by the horizontal mass movement, which changes the time step size, the scale's length divided by the scale's velocity [14].

\section{Resistance component analysis}

The monohull motorboat modification analysis into a catamaran is identified in the total resistance, viscous resistance, friction, and wave contours.

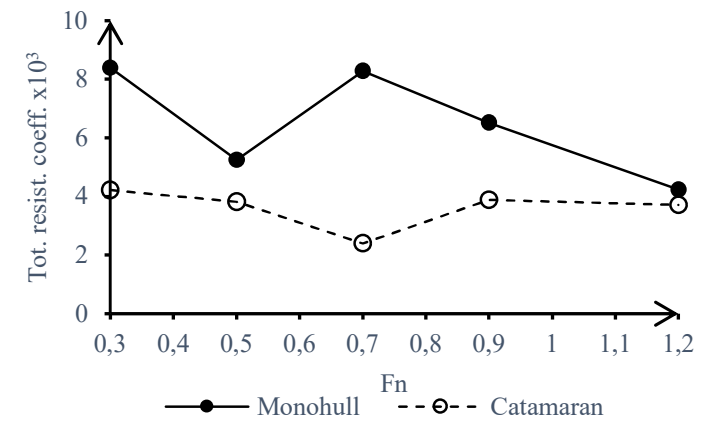

Fig. 7. Comparison of motorboat monohull dan catamaran on total resistance coefficient, $C_{T}$

The total resistance coefficient shows the total resistance comparison of both hulls in Figure 7 . Furthermore, Figures 8-10 show the results of the ship's resistance component calculation displayed in the 
coefficient of viscous, frictional, and wave resistance. In the total resistance coefficient (Figure 7), both hull models provide a decrease along with an increase in speed. The average comparison of the total resistance results between the two is $45 \%$. In the viscosity resistance coefficient (Figure 8), both models show a constant decrease, with the average $C_{V}$ value of the catamaran being $9 \%$ smaller than the monohull. In the friction resistance coefficient (Figure 9), monohulls have a smaller average, with a difference of $0.3 \%$ compared to catamarans. Meanwhile, in the wave resistance (Figure 10), the catamaran experienced an average decrease of up to $66 \%$ from the monohull.

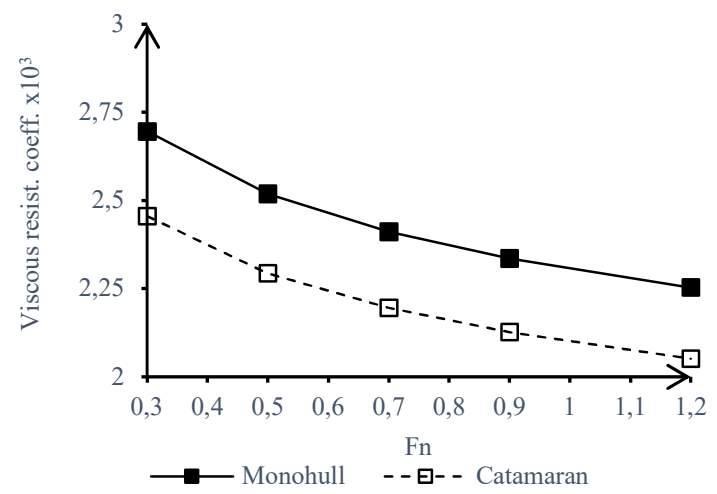

Fig. 8. Comparison of motorboat monohull dan catamaran on viscous resistance coefficient, $C_{V}$

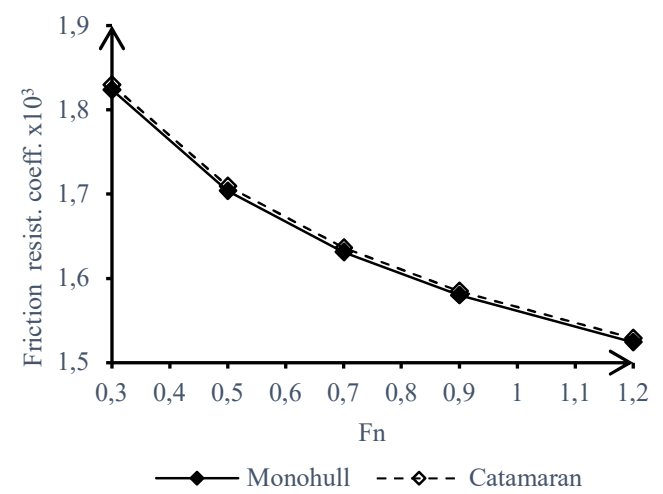

Fig. 9. Comparison of motorboat monohull dan catamaran on friction resistance coefficient, $C_{F}$

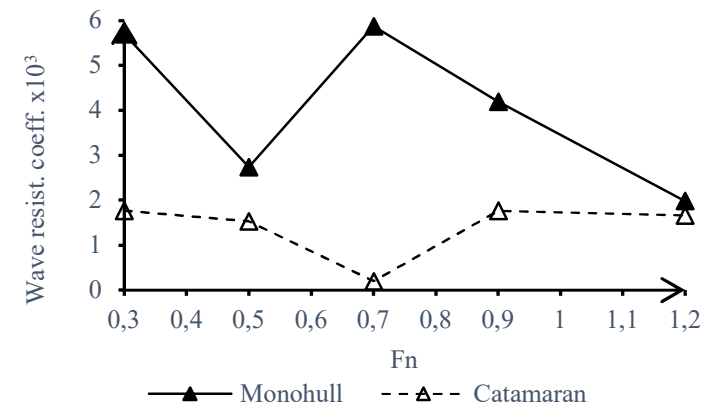

Fig.10. Comparison of motorboat monohull dan catamaran on wave resistance coefficient, $C_{W}$

Figure $11-13$ shows the wave pattern of CFD simulation results at low speed (Fn 0.3), medium speed (Fn 0.7), and high speed (1.2). The wave pattern seems to have a reasonably good consistency between the qualitative features of the wedge contour area enveloping the stern ship and the calculated wave resistance of the two models at each speed.
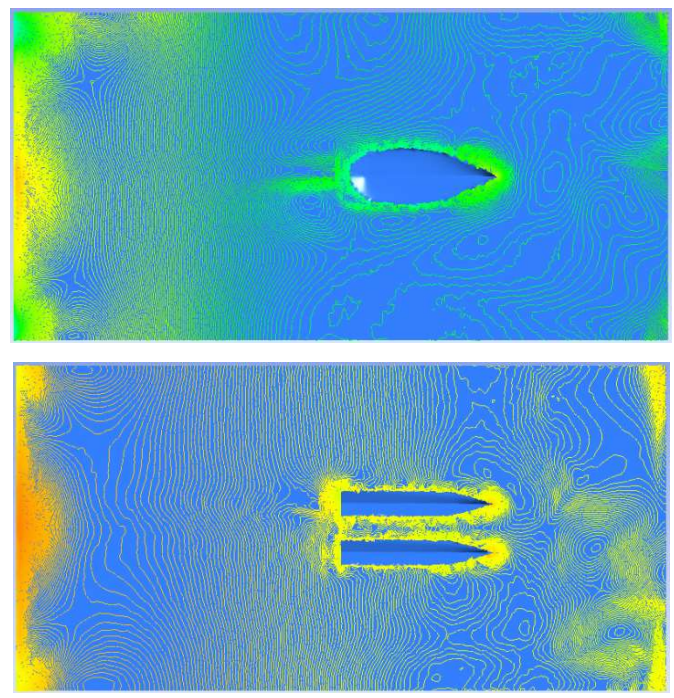

Fig.11. Comparison on contour wave monohull (top) and catamaran (bottom) at Fn 0.3
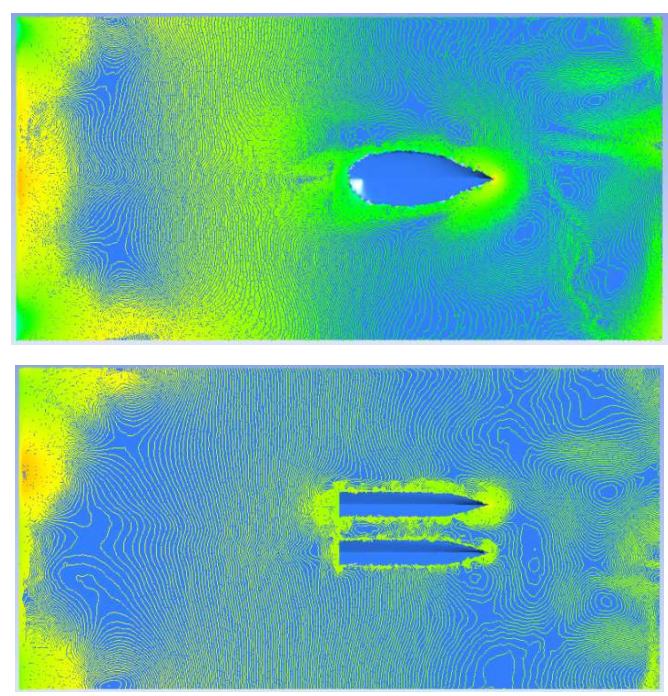

Fig.12. Comparison on contour wave monohull (top) and catamaran (bottom) at Fn 0.7

\section{Results and Discussion}

Figure 7 shows that catamaran has a total resistance that is smaller than the overall speed analyzed. However, there was a significant decrease in monohull at Fn 0.7, and on the contrary, there was a reasonably more decrease. 

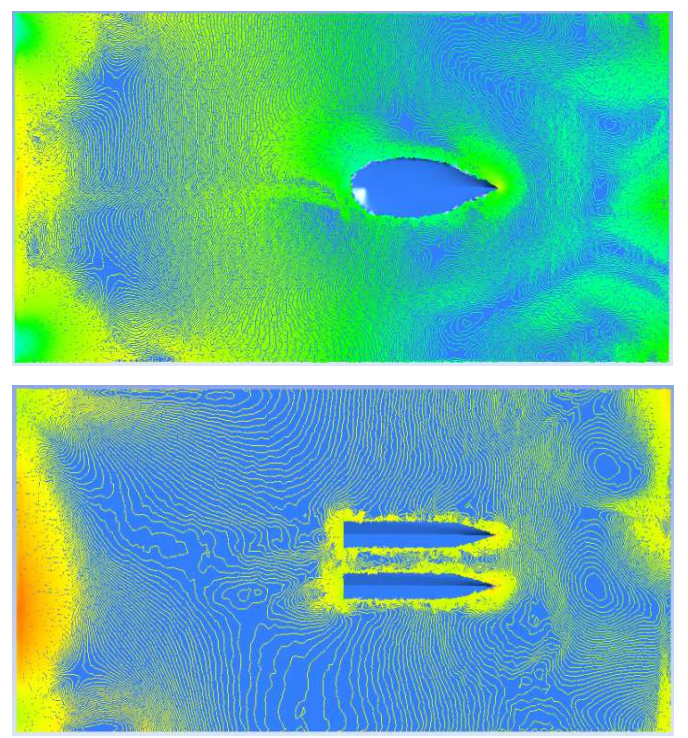

Fig.13. Comparison on contour wave monohull (top) and catamaran (bottom) at Fn 1.2

Looking at Figure 8, the viscous resistance coefficient, $C_{V}$ tends to decrease, which indicates that the catamaran has a smaller value than the monohull. It is due to the influence of the catamaran's form factor, which is more favorable with reduced interference with the $\mathrm{S} / \mathrm{L}$ ratio, which can be considered entirely appropriate. Besides, hull chine has a lifting force in line with increased speed to reduce the viscosity. The friction coefficient $\left(C_{F}\right)$

Figure 9 shows the same trend as the viscosity coefficient, but the friction value of the monohull is slightly smaller than that of the catamaran. It is possible cause the wet surface area of the two models is almost the same.

Figure 10, the wave coefficient of the catamaran shows a much smaller value than that of the monohull. The $\mathrm{S} / \mathrm{L}$ distance ratio factor that is quite precise can produce destructive waves where the waves that occur between the catamaran's hulls will cancel each other to minimize interference.

Furthermore, the contour at Fn 0.7 in Figure 12 shows conformity with the calculation of wave resistance where it appears that the waves formed between 2 hulls on the catamaran are negligible compared to Fn 0.3 and 1.2 indicates the occurrence of waves canceling each other out. On the contrary, the monohull contour is shown where at Fn 0.7 (Figure 12), the waves formed are more significant according to the calculation of fluctuating wave resistance compared to Fn 1.2.

\section{Conclusion}

In general, all results calculated by CFD simulations for all resistance components and wave contours of monohull and resistance catamarans have shown that catamarans are quite profitable to replace the hull of the Petrus Sianturi motorboat. Although this study did not compare the experimental results, the simulation has been carried out very carefully regarding the ITTC 2011 rules regarding "Practical Guidelines for Ship CFD Applications." The average comparison of the total resistance coefficient $\left(\mathrm{C}_{\mathrm{T}}\right)$ of monohulls and catamarans at the same total length and displacement shows a decrease in the total resistance coefficient of $45 \%$.

This study is expected to provide practical information for modifying a monohull motorboat into a catamaran by maintaining its length and displacement volume. More complex analysis is needed with testing in towing tanks and similar simulations to support the results of this study.

\section{References}

1. D. Savitsky, D.A. Dingee, Some interference effects between two flat surfaces planing parallel to each other at high speed. Journal of the Aeronautical Sciences, 21(6), pp.419-420 (1954)

2. J. He, C .Zhang, Y. Zhu, L. Zou, W. Li, F. Noblesse, Interference effects on the Kelvin wake of a catamaran represented via a hull-surface distribution of sources. European Journal of Mechanics-B/Fluids, 56, pp.1-12 (2016)

3. R. Broglia, S. Zaghi, A. Di Mascio, Numerical simulation of interference effects for a high-speed catamaran. Journal of marine science and technology, 16(3), pp.254-269 (2011)

4. A. Jamaluddin, I. Ketut aria pria utama, \& M. Arief, Slender Body Method, in Balai Pengkajian Dan Penelitian Hidrodinamika, 1-9 (2002)

5. P.Y. Li, Y.M. Qiu, \& M.T. Gu, Study of trimaran wavemaking resistance with numerical calculation and experiments. Journal of Hydrodynamic Series B-English Edition 14(2): 99-105 (2002)

6. S. Tarafder, Third order contribution to the wavemaking resistance of a ship at finite depth of water. Ocean engineering 34(1):32-44 (2007)

7. W. Sulistyawati, Yanuar, AS. Pamitran, The influences of diversity hull shapes and outriggers arrangement in pentamaran systems. Energy Reports, 6, pp.595-600 (2020)

8. Z. Wang, L.U. Xiao-ping, Research on high speed surface warship with bulbous bow. Journal of Hydrodynamics (Ser. A) 6:015 (2006)

9. H. Duan-fen. Research on the method and calculation of the new slender-ship wave resistance theory. Journal of Hydrodynamics, Ser. B, 15(4):124 (2003)

10. ITTC, Recommended Procedures and Guidelines Practical Guidelines for Ship CFD Applications, 7.5-03-02-03 (2011)

11. G.S. Bari, K.I. Matveev, Hydrodynamic modeling of planing catamarans with symmetric hulls. Ocean Engineering, 115:60-66 (2016)

12. W. Sulistyawati, Yanuar, , A.S. Pamitran, Michell Investigation of the Significant Influence on the Hydrodynamic of a Warp-Chine Pentamaran. Journal of Ship Production and Design, 36(03), pp.202-212 (2020) 
13. H.K. Versteeg, W. Malalasekera, An introduction to computational fluid dynamics: the finite volume method. Pearson education (2007)

14. J.W. Seo, D.M. Seol, J.H. Lee, S.H. Rhee, Flexible CFD meshing strategy for prediction of ship resistance and propulsion performance, Inter $\mathrm{J}$. Nav. Arch. Oc. Eng. 2 pp 139-14 (2010) 